\title{
What messages does social marketing advertising send? A content analysis of advertisements aiming to minimise harm from alcohol consumption
}

\section{Introduction}

Problems associated with harmful alcohol consumption have become a worldwide issue (Farrell and Gordon, 2012), and the consequences of excessive alcohol consumption have serious implications for public health: the World Health Organization estimated that 3.3 million people worldwide died of alcohol-related causes in 2012 (WHO, 2014). While the negative consequences of alcohol consumption remain one of the most pressing problems for government and society in many countries, the role of social marketing as a tool for shaping a responsible alcohol consumption culture has grown in significance (Kotler et al., 2002). Studies have demonstrated that social marketing campaigns aimed at preventing harmful drinking behaviours can be effective in addressing this problem (Yanovitzky and Stryker, 2001; Gordon et al., 2006; Hastings and McDermott, 2006). As the application of social marketing to the design and implementation of campaigns that aim to minimise problems caused by alcohol consumption has increased in popularity and use within the public health sector (Glider and Midyett, 2001; Grier and Bryant, 2005; Cismaru et al., 2009; Tay, 2005), this research focuses specifically on the communication aspect of social marketing in the form of social marketing advertising (Arthur and Quester, 2003).

Social marketing advertising embraces a wide range of approaches to overcoming harmful alcohol consumption behaviours. In particular, social marketing campaigns incite feelings of fear (Hastings et al., 2004), shame and guilt (Agrawal and Duhachek, 2010); use nudging (French, 2011; Marteau, 2011); and employ empowerment techniques to motivate people to take control of their lives by promoting the notion of freedom of choice (Grace, 1991; Rissel, 1994; John et al., 2009). Although studies suggest that certain types of approaches (e.g. those used to incite shame, guilt, or fear) can be fraught with negative outcomes (Agrawal and Duhabeck, 2010; Marteau, 2011; Hastings et al., 2004), no studies to date have explored how widespread those approaches are in the social marketing advertising landscape. Thus, there is a need to investigate what types of approaches are most commonly used in social marketing advertising. This study therefore seeks to explore what types of approaches and messages are most prevalent in social marketing advertising campaigns that aim to minimise harm from excess alcohol consumption. Specifically, this research aims to address two research questions: first, which approach(es), namely empowerment and/or patronising are evident in social marketing advertising messages? Second, which of the key components of the positive and negative messages are used in social marketing advertisements? In the following literature review, the main positive and negative consequences of alcohol consumption are explored, focusing on aspects such as physical health, mental health and social wellbeing. Following this, two main approaches to social marketing advertising - that is, empowerment and patronising approaches - will be discussed, and their key components identified.

\section{Literature review}

\section{Consequences of alcohol consumption}

The overwhelming majority of research into alcohol consumption concentrates on the related negative consequences (Steele and Josephs, 1990; Wechsler et al., 1994; Rundle-Thiele et al., 2008). However, it would be restrictive to consider alcohol consumption only from the negative angle, as positive associations with alcohol tend to influence drinking behaviour more profoundly than negative ones do (Park, 2004; Steele and Josephs, 1990). The key areas of positive and negative effects of alcohol use can be divided into three main groups: physical health, mental health and social wellbeing. 
Moderate alcohol consumption may be beneficial for physical health, subject to such individual conditions as age, sex, family history and specific medical issues (Klatsky, 2004). The large body of research on alcohol and physical health indicates that moderate doses of alcohol might be beneficial not only for preventing cardiovascular disease, but also for reducing the risk of gallstones and type II diabetes (Anderson and Baumberg, 2006; Goldberg et al., 1999), and offering protective effects in relation to other medical conditions (Goldberg et al., 1999; Daviglus et al., 2011; Neafsey and Collins, 2011; Sacco et al., 1999). However, as an addictive drug, alcohol is also a cause of around 60 types of conditions and diseases, including injures, gastrointestinal conditions, lung conditions, immunological disorders, cancers, skeletal and muscular diseases, reproductive disorders and pre-natal harm, such as low birth-weight and increased risk of prematurity (Rehm et al., 2003). For most of these conditions, alcohol increases the risk in a dose-dependent manner: the higher the alcohol consumption, the greater the risk and possible severity of the abovementioned diseases (Anderson and Baumberg, 2006).

In regards to the relationship between alcohol and mental health, one of the positive outcomes of moderate alcohol consumption is the reduction of psychological stress (Goldberg et al., 1999; Steele and Josephs, 1990). However, a prolonged influence of alcohol may also take an opposite role, as an aggravator of psychological stresses (Cargiulo, 2007), since the effect of alcohol is determined by the dose level and the longevity of intake (Williams, 1966). Furthermore, alcohol consumption has been recognised as a trigger of mental disorders. It can alter our mood, and thus incite behavioural changes. Long-term alcohol consumption may lead to psychological problems such as manias, panic disorders and phobias (Carguilo, 2007). Additionally, alcohol may amplify both positive and negative emotions, leading to major depression and/or anxiety disorders (Carguilo, 2007; RundleThiele et al., 2008).

Alcohol is also intricately linked with several positive and negative consequences for social wellbeing. For example, previous research has explored issues such as the positive role of alcohol consumption in enhancing self-evaluation (Banaji and Steele, 1989; Park, 2004; Steele and Joseph, 1990), facilitating socialisation (Park, 2004; Park and Grant, 2005; Siemieniako and Kubacki, 2011), increasing a sense of togetherness (Caan, 2013; Pettigrew et al., 2000; Szmigin et al., 2008), improving creativity (Beveridge and Yorston, 1999; Park, 2004; Park and Grant, 2005) and being a source of pleasure (Park, 2004, Park and Grant, 2005; Sheehan and Ridge, 2001; Wright, 1999). However, there is also strong evidence of alcohol's negative influence on relationships and work arising from increased aggression (Lang et al., 1975; Siemeniako and Kubacki, 2011) and antisocial behaviours (Wechsler and Nelson, 2008). Alcohol consumption may also lead to feelings of regret (Wechsler, 1994; Park, 2004; Park and Grant, 2005), poor academic performance (Hill et al., 2005; Wechsler and Nelson, 2008), unplanned and/or unprotected sex (Hill et al., 2005; Park; 2004, Wechsler, 1994; Wechsler and Nelson, 2008) and sexual assaults (Cismaru et al., 2008).

\section{Social marketing advertising approaches}

Social marketing research distinguishes between two main approaches: empowering and patronising. On the one hand, the empowerment philosophy is based on the assumption that human beings have the ability to make choices, and are responsible for the consequences of these choices (Feste and Anderson, 1995). As Rappaport (1981) suggested, the major aim of empowerment is to increase people's ability to control their lives by encouraging freedom of choice, and using questions, storytelling and behavioural language, and engaging people in 
personal development. Once the value of improved wellbeing has been discovered and understood by individuals through reflection and judgment, it becomes prominent in the individuals' lives. Consequently, the benefits and costs of new behaviour start to look different to the individual, and the motivation to make sacrifices for the desired behaviour will become more appealing (John et al., 2009). The patronising approach, on the other hand, questions the relationship between policy-makers and society, whether via a mutual respect between adults, or a patronising, parent-child approach, wherein a health authority attempts to redirect people to obtain a desired behaviour.

In the empowerment approach, three types of technique to promote desired behaviour may be used. First, the empowerment approach emphasises free choice in advertising messages by providing different behavioural options and avoiding telling the target market how they should and should not behave (Grace, 1991; Rissel, 1994; John et al., 2009). Second, the empowerment approach employs questions, storytelling and behavioural language (Feste and Anderson, 1995). Questions encourage people to obtain new information and knowledge; storytelling makes theory more appealing to people, as it tries to connect stories with people's beliefs; and behavioural language aims to encourage people to make their own choices and take responsibility for their own actions using verbs such as 'decide', 'describe', 'identify' and 'list' (Kettunen et al., 2001). The third empowerment technique attempts to engage people in personal development. It implies that individuals can be enabled to take a step back from their day-to-day experience and become thirsty for knowledge, and thus reach new heights of information and judgement (John et al., 2009).

The patronising approach uses three types of technique to promote desired behaviour from the target audience. First, it implies a process in which no choice is offered because freedom is restricted; therefore, a social marketing approach that offers no choice is disempowering (Hastings and Saren, 2003). Nudging is a second type of patronising technique (French, 2011); here, the organisations that create the social marketing advertisements are positioned as experts in the field. The focus of nudging is on stimulating positive choices by developing the conditions, social systems or environments in which people prefer to make choices for their own benefit, and thus it incites them to make a small effort to choose a socially desirable behaviour. The third type of patronising technique is the use of fear, shame and guilt in social marketing advertising. There are two types of fear appeal that exist in the social marketing context (Kenyon and Wood, 2011): physical fear, which implies low fear, such as easily avoidable accidents, and high fear, such as intense pain, substantial harm or death; and fear of psychological and social harm, which may include a fear of lack of social skills and rejection (Kenyon and Wood, 2011). However, some studies indicate that the fear appeal is not effective when it is not personally relevant to the audience (Viljoen et al., 2009). Shame and guilt are considered self-conscious emotions, as they often involve perceptions of the self and frequently carry very strong personal implications (Agrawal and Duhacheck, 2010). Both of these emotions are negative, and suggest an unpleasant state; thus, people are motivated to avoid them. Additionally, when people project shame or guilt messages onto their own actions, potential negative consequences appear less likely due to defensive processing (Agrawal and Duhacheck, 2010). In other words, an advertisement that contains emotions of guilt or shame might provoke a defence mechanism that would lead to ineffective processing of the message. Again, the emotional appeal of strong emotions such as fear, shame and guilt suggests to the target audience that there are no alternative options to experiencing these feelings if they engage in the behaviour depicted in the advertisements. The approach that offers no choice is thus considered disempowering and patronising (Hastings and Saren, 
2003). Therefore, the patronising approach can be identified through the restrictions it imposes onto freedom of choice, and its use of nudging, fear, shame and guilt.

Taken together, for the purpose of this research the interplay between alcohol consumption and social marketing advertising literature can be classified into four main categories (see Table 1). The first two cover negative and positive consequences of alcohol consumption in the context of mental well-being, physical health and social well-being. Further, social marketing advertising messages can be classified as adopting empowering and patronising approaches. Empowering approaches include promoting freedom of choice within the advertisement, the use of questions, storytelling and behavioural language, and efforts to engage people in personal development. Patronising approaches include lack of freedom of choice, nudging and conforming to imposed authoritarian norms, and the use of strong emotions such as fear, shame and guilt. The following section presents the methods and procedure used in this study.

\section{Method}

The present study offers a comprehensive examination of social marketing advertisements that target harmful alcohol consumption, and applies the content analysis method to identify the main themes and messages in a sample of social marketing advertisements. Content analysis has been described by Holsti (1968) as 'any technique for making inferences by systematically and objectively identifying special characteristics of messages' (p. 608). Content analysis commonly involves quantitative description of the specific characteristics of messages, and remains one of the most popular methods by which to study the content of communication (Prasad, 2008).

A total of 14 social marketing advertising campaigns, including 29 advertisements, were identified via Google from health-related government websites such as the UK Government Department of Health, Health Canada, the National Institutes of Health, the Australian Department of Health and the US Department of Health and Human Services. The search was performed using a combination of the following key terms: social marketing campaigns, antidrinking campaigns, anti-drinking behaviour campaigns, anti-drinking advertising, antidrinking advertisements, anti-binge drinking advertisement, anti-binge drinking campaigns. Full list of campaigns and advertisements can be found in Appendix 1.

The social marketing advertising campaigns were limited by three main exclusion criteria: time period, English language and the presence of video advertisements. Considering that social marketing is a fast-growing field, only campaigns from 2000 to 2013 were considered (in addition, most video advertisements from campaigns dated pre-2000 are not available on the Internet). In order to ensure consistency in our interpretation, only social marketing interventions created by English-speaking countries were included in the study. Several earlier studies have focused on a similar comparison analysis, such as content analyses of drink-driving campaigns (Cismaru et al., 2009), and of social marketing campaigns aimed at moderating alcohol intake among young people (Cismaru et al., 2008). The third criterion, the presence of a video advertisement, was set due to the fact that in comparison to print advertisements and Internet sites, video advertisements reach a broader audience and are widely available on the Internet. Old print advertisements would have been much more difficult to collect.

The advertisements were transcribed, resulting in 29 pages that included all of the spoken and written text identified. Other data, such as that relating to images, were gathered by watching 
the advertisements and taking notes. The analytical procedures identified by Prasad (2008) were followed; this included selecting the communications sample, developing the analytical framework following a literature review, and coding the data. In this research, coding units were defined by the analysis of positive and negative consequences of alcohol consumption (e.g. the unit of analysis was 'unhappy relationships' or 'increased aggression') and analysis of empowerment and patronising approaches used (e.g. the unit of analysis was 'fear appeal' or 'behavioural language').

The analytical framework for this research was developed following the literature review, and identification of the key constructs (see Table 1). It reflects both of the key approaches in social marketing advertising: empowering and patronising, and the consequences of alcohol consumption, both positive and negative. As noted above, the empowering approach focuses on promoting freedom of choice in the advertisement, as well as the use of questions, storytelling and behavioural language, and makes efforts to engage people in personal development. The consequences of alcohol consumption portrayed in the analysed advertisements related to physical and mental health and social well-being.

Insert Table 1 About Here

In order to increase the validity of the study, two other researchers within the same field of study, social marketing, were invited to assist with the process of data analysis, and one researcher was invited to assist with the data verification (investigator triangulation; Denzin, 1978). Each investigator examined the data using the same analytical framework. The results from each researcher were then discussed and collated in order to create a deeper and broader understanding of how these different researchers perceive the content of the social marketing advertisements.

\section{Findings}

The 14 social marketing campaigns, which included 29 video advertisements, were identified via Google and the health-related government websites noted above. The analytical framework was developed following the literature review, with the key constructs identified including: freedom of choice; questions, storytelling and behavioural language; efforts by people to engage in personal development; no freedom of choice; nudging and conforming to imposed authoritarian norms; fear, shame and guilt; mental health, physical health and social wellbeing as positive consequences of alcohol consumption; and harm to mental health, physical health and social wellbeing as negative consequences of alcohol consumption (see Table 1).

Table 2 shows the prevalence of the various approaches and messages used in the social marketing campaigns by percentage of use, while Table 3 displays the use of the main subcategories of approaches and messages used in the social marketing campaigns. 
Insert Table 3 About Here

\section{Discussion}

This study aimed to explore the types of approaches and messages that are most prevalent in social marketing advertising campaigns that aim to minimise harm from excess alcohol consumption. The framework constructed following the literature review was used to analyse 29 social marketing advertisements. The framework included both positive and negative consequences of alcohol consumption, and two main social marketing advertising approaches identified in the literature: empowering and patronising. The empowering approach focuses on promoting freedom of choice within the advertisement, and using of questions, storytelling and behavioural language, and efforts to engage people in personal development. The consequences of alcohol consumption portrayed in the analysed advertisements related to physical and mental health, and social wellbeing.

This study found that the patronising approach was most frequently used in the social marketing advertisements analysed. This approach was used in 71 per cent $(n=10)$ of the campaigns, and 86 per cent $(n=25)$ of the advertisements. The patronising approach was said to include three key sub-categories: 'no freedom of choice', 'nudging and conforming to imposed authoritarian norms', and engagement of strong emotions such as 'fear, shame and guilt'. The 'no freedom of choice' sub-category has been earlier associated in the literature with disempowering and patronising messages (Hasting and Saren, 2003). Interestingly, this component of the patronising approach was used in the advertisements by presenting situations that indirectly suggested that there is no free choice. According to the analysis, this sub-category was employed in 21 per cent $(n=6)$ of the advertisements, and 36 per cent $(n=5)$ of the campaigns. 'Nudging', on the other hand, is a type of patronising approach which implies that the organisations creating the interventions are experts in the field (French, 2011). The focus of nudging is on stimulating positive action by developing the conditions, social systems or environments in which people prefer to make choices for their own benefit (and thus display socially desirable behaviour). This sub-category was employed in 41 per cent $(n=12)$ of the advertisements and 29 per cent $(n=4)$ of the campaigns. The analysis shows that a dependency on patronising techniques was manifest in the advertisements in different forms, such as relationships between health authorities and parents; security staff and venues; government and the public; or friends and individuals. Finally, advertising using fear, shame and guilt as the main type of appeal can be related to the patronising approach. Agrawal and Duhachek (2010) argued that these strong emotions are widely used in social marketing advertising campaigns in order to reduce harmful behaviours in society - a statement that is supported by this study, which shows that this emotional appeal was employed in about 72 per cent of the advertisements $(n=21)$ and in almost 71 per cent $(n=10)$ of the campaigns.

The empowerment approach implies personal development, consciousness growth, social action and participation (Rissel, 1994). The advertisements that employed this technique show the willingness of the advertiser to communicate a message of a personal growth, either by personal example (such as the 'Hello Sunday Morning' campaign) or by using 
encouraging phrases, so that the audience will start their own cognitive process (for example, the 'What are you doing to yourself?' series, and 'Had enough, ease up on the drink', see Appendix 1). The empowerment approach was employed by 50 per cent $(n=7)$ of the campaigns, and 55 per cent $(n=16)$ of all advertisements. The empowerment approach in social marketing applies principles that aim to involve people in order to be responsible for their own wellbeing. This approach encourages the target audience to take control of their own lives and rights, and thus, by default, promotes freedom of choice. Three key criteria defining this approach are: 'freedom of choice', 'efforts by people to engage in personal growth', and the key techniques of the empowerment approach, namely 'questions, storytelling and behavioural language'. The 'freedom of choice' sub-category represents the notion of free will, which is promoted to each individual and suggests to them that there is always an alternative choice. The empowerment approach is claimed to be a better option for persuading people to perform a desired behaviour, due to the fact that it does so by promoting freedom of choice to the target audience, rather than patronising it (Grace, 1991; Rissel, 1994; John et al., 2009). However, the present analysis shows that only 29 per cent $(n=4)$ of all campaigns and 31 per cent $(n=9)$ of all advertisements applied this component. The empowerment approach also applies various tools in order to incite a desired change in behaviour, one of which is 'questions, storytelling and behavioural language' (Feste and Anderson, 1995) - though this sub-category was used by only 29 per cent $(n=4)$ of the campaigns and 38 per cent $(\mathrm{n}=11)$ of the video advertisements. Additionally, the 'behavioural language' component of this sub-category was not used in video advertisements at all. The final sub-category, 'efforts by people to engage in personal development,' was applied in 36 per cent $(n=5)$ of all campaigns, and 17 per cent $(n=5)$ of all advertisements.

The next category, 'negative consequences of alcohol consumption', was used in 79 per cent $(n=11)$ of the campaigns and 93 per cent $(n=27)$ of the advertisements, and thus was the most prevalent category. Alcohol is associated with psychological health issues, as well as with physical problems (Cargiulo, 2007); it has been identified as a cause of around 60 types of conditions and diseases (Rehm et al., 2003). The negative consequences can be divided into three groups: mental health, physical health and social wellbeing. The 'mental health' subcategory was used by 21 per cent $(n=3)$ of the campaigns and 10 per cent $(n=3)$ of the advertisements. This sub-category was used least in the 'negative consequences of alcohol consumption' category. The 'physical health' sub-category was shown to have been used in 79 per cent $(n=11)$ of the campaigns and 76 per cent $(n=22)$ of the advertisements, making it the most popular sub-category in the 'negative consequences of alcohol consumption' category, as well as the most prevalent theme among all the categories displayed in Table 3. It might be assumed that the popularity of this sub-category is related to social marketers' willingness to point out health problems and make the target audience feel frightened for their health. Further, the 'social wellbeing' sub-category was applied in 71 per cent $(n=10)$ of the campaigns and 66 per cent $(n=19)$ of the advertisements, making it the third most prevalent theme used in the advertisements.

The final category, 'positive consequences of alcohol consumption', was the least frequently used category, having been identified in only in 36 per cent $(n=5)$ of the campaigns and 41 per cent $(n=12)$ of the advertisements. The positive consequences of alcohol consumption are often more influential in shaping consumption behaviours than are the negative consequences (Park, 2004); thus, it is surprising to find that social marketers tend not to use this type of message. The positive consequences category has been divided into three main groups: mental health, physical health and social wellbeing. The 'mental health' sub-category was applied by 14 per cent $(n=2)$ of the campaigns and 10 per cent $(n=3)$ of the advertisements. 
Finally, this research indicates that the 'physical health' sub-category was not used in the social marketing campaigns studied. However, with regards to the 'social wellbeing' category, the analysis revealed that 21 per cent $(n=3)$ of the campaigns and 31 per cent $(n=9)$ of the advertisements used this sub-category as a component. According to previous research, alcohol is intricately linked with several benefits to social wellbeing (Christiansen et al., 1985; Szmigin et al., 2008), yet very few campaigns used this approach.

\section{Conclusions}

The aim of this study was to explore what types of approaches and messages are most prevalent in social marketing advertisements that aim to minimise harm from excess alcohol consumption. This study identified the presence of the main components of the empowerment and patronising approaches, as well as the key components of the positive and negative messages used in social marketing advertisements. The patronising approach and a strong focus on the negative consequences of alcohol consumption are prevalent in contemporary social marketing campaigns aimed at minimising harmful drinking behaviours. Specifically, fear, shame or guilt appeal are most commonly used to communicate the desired message to the public. The evidence indicated use of the patronising approach in 25 advertisements and 10 campaigns, while the negative consequences of alcohol consumption were presented in 27 advertisements and 11 campaigns. Further, a consistent pattern for the use of the prevalent patronising approach sub-category, 'fear, shame and guilt', was identified, as well as for the two sub-categories of negative consequences of alcohol consumption, 'social wellbeing' and 'physical health'. A total of 14 out of 29 advertisements contained both the 'fear, shame and guilt' and 'social wellbeing' sub-categories, while 18 out of 29 advertisements contained both the 'fear, shame and guilt' and 'physical health' sub-categories. Thus, it can be concluded that the patronising approach applies negative messages that focus on social wellbeing and physical health in order to influence behaviour.

However, the large body of previous research suggests that the use of emotions such as fear, shame and guilt may not be effective (Lewis et al., 2007; Viljoen et al., 2009; Agrawal and Duhachek, 2010). As mentioned above, there is a tendency for people to dismiss and discount fear-based messages as irrelevant; the target audience has been shown to engage in defensive avoidance behaviours, instead of acting to deal with the jeopardy associated with the risky behaviour conveyed in the social marketing message, as the appeal is not considered personally relevant to the audience (Lewis et al., 2007). The other two emotions, shame and guilt, are negative and suggest an unpleasant state; thus, people are motivated to avoid them. When people project shame or guilt messages onto their own actions potential negative consequences appear less likely due to defensive processing (Agrawal and Duhacheck, 2010). In other words, an advertisement that contains emotions of guilt or shame may provoke a defence mechanism that would then lead to ineffective processing of the message.

The results of this study suggest that it is time for social marketing advertising to move beyond patronising approaches and facilitate and support behaviour change through empowerment by providing consumers with alternative behavioural options. Social marketing is often perceived by consumers as manipulative, unethical and expensive (Andreasen, 2002; Brenkert, 2002; Pang and Kubacki, 2015), and is at risk of being reduced to a form of patronising nanny-statism and a tool in a political agenda. Donovan and Henley (2010) highlighted that social marketing too often takes a paternalistic approach to encouraging behavioural change, and this research provides further evidence for the prevalence of patronising techniques in social marketing advertising. In this research, techniques such as use of questions, storytelling and behavioural language, and attempts to engage people in 
personal development were identified as being rarely used in social marketing advertising. Social marketers need to recognise the limitations and risks of patronising techniques and move away from what Cherrier and Gurrieri (2014) call 'expert-driven social control' techniques towards techniques that facilitate empowerment. Otherwise, social marketing runs the risk of marginalising, excluding or even stigmatising social groups that do not conform to the norms promoted by the campaigns (Gurrieri et al., 2013). More social marketing efforts should be directed towards identifying how to motivate people to take responsibility for their lives and wellbeing, as they ultimately have the ability to make choices and are responsible for the consequences of these choices (Feste and Anderson, 1995). Yet, with its identification of the heavy focus on negative consequences of alcohol consumption, our research shows that social marketing advertising only sporadically provides consumers with alternative behavioural options that promote responsible consumption. The two sub-categories within positive consequences of alcohol consumption, 'physical health' and 'mental health', were used in a few instances. These findings are consistent with previous research by Steele and Josephs (1990) and Park (2004), who argued that positive consequences of alcohol consumption are often more influential in shaping consumption behaviour, compared to the risks associated with hazardous drinking, and therefore should feature more prominently in social marketing advertising that attempts to influence alcohol consumption.

\section{Limitations and future research}

There are several limitations to this study. First, we excluded social marketing interventions without video advertisements; in other words, many social marketing campaigns directed at reducing harmful drinking behaviour that apply other marketing tools (such as print media, promotional events and outdoor advertising), but lack video advertisements, were not assessed in this study, which meant that much available data was not included in the research. Second, while the gathered campaigns originated from English-speaking countries, this study was unable to provide insights into the trends in different countries throughout the world. Third, the collected data were lacking in terms of the number of campaigns originating from the chosen countries, since unequal numbers of campaigns from each country were analysed (Australia $(n=8)$, New Zealand $(n=2)$, Canada $(n=1)$, UK $(n=3)$ ). This fact limited comparison of the usage of social marketing approaches and messages between these countries.

Four key aspects were identified for further research. First, investigations into the effectiveness of the empowerment and patronising approaches in social marketing can be conducted. Second, social marketing interventions aimed at preventing harmful drinking behaviour in non-English speaking parts of the world can be explored. Third, studies of the actual perceptions of target audiences with regards to the empowerment and patronising approaches applied in social marketing campaigns can be carried out. Finally, future research can be directed at analysing different types of social marketing tools, such as print media, events and outdoor advertisements. 


\section{Bibliography}

Agrawal N, Duhachek A. 2010. Emotional compatibility and the effectiveness of antidrinking messages: A defensive processing perspective on shame and guilt. Journal of Marketing Research 47(2):263-273.

Andreasen AR. 2002. Marketing social marketing in the social change marketplace. Journal of Public Policy and Marketing 3(1):1-13.

Anderson P, Baumberg B. 2006. Alcohol in Europe: a public health perspective, A report for the European Commission.

Arthur D, Quester, P. 2003. The ethicality of using fear for social advertising. Australasian Marketing Journal 11(1):12-27.

Banaji MR, Steele CM. 1989. Alcohol and self-evaluation: Is a social cognition approach beneficial?. Social Cognition 7(2):137-151.

Beveridge A, Yorston G. 1999. I drink, therefore I am: alcohol and creativity. Journal of the Royal Society of Medicine 92(12):646-648.

Brenkert GG. 2002. Ethical challenges of social marketing. Journal of Public Policy \& Marketing 21(1):14-25.

Caan W. 2013. Alcohol and the family. Contemporary Social Science 8(1):8-17.

Cargiulo T. 2007. Understanding the health impact of alcohol dependence. American Journal of Health-System Pharmacy 64(3):5-11.

Cherrier H, Gurrieri L. 2014, Framing social marketing as a system of interaction: a neoinstitutional approach to alcohol abstinence. Journal of Marketing Management 30(7/8).

Christiansen BA, Goldman MS, Brown SA. 1985. The differential development of adolescent alcohol expectancies may predict adult alcoholism. Addictive Behaviors 10(3):299306.

Cismaru M, Lavack AM, Markewich E. 2008. Alcohol consumption among young consumers: a review and recommendations. Young Consumers: Insight and Ideas for Responsible Marketers 9(4):282-296.

Cismaru M, Lavack AM, Markevich E. 2009. Social marketing campaigns aimed at preventing drunk driving. International Marketing Review 26(3):292-311.

Daviglus ML, Plassman BL, Pirzada A, et al. 2011. Risk factors and preventive interventions for Alzheimer disease: State of the science. Archives of Neurology 68(9):1185-1190.

Denzin NK. 1978. The research act: A theoretical introduction to sociological methods. McGraw-Hill. New York. NY.

Donovan R, Henley N. 2010, Principles and Practice of Social Marketing: An International Perspective, Cambridge University Press, Cambridge.

Farrell T, Gordon R. 2012. Critical social marketing: investigating alcohol marketing in the developing world. Journal of Social Marketing 2(2):138-156.

Feste C, Anderson MR. 1995. Empowerment: from philosophy to practice. Patient Education and Counseling 26(1-3):139-144.

Glider SJ, Midyett BP. 2001. Challenging the collegiate rite of passage: A campus-wide social marketing media campaign to reduce binge drinking Journal of Drug Education 31(2):207-220.

Gordon R, McDermott L, Stead M, Angus K. 2006. The effectiveness of social marketing interventions for health improvement: What's the evidence?. Public Health 120(12):1133-1139.

Goldberg DM, Soleas GJ, Levesque M. 1999. Moderate alcohol consumption: the gentle face of Janus. Clinical Biochemistry 32(7):505-518.

Grace VM. 1991. The marketing of empowerment and the construction of the health 
consumer: A critique of health promotion. International Journal of Health Services, 21(2):329-343.

Grier S, Bryant CA. 2005. Social marketing in public health. Annual Review of Public Health 26:319-339.

Gurrieri L, Previte J, Brace-Govan J. 2013. Women's bodies as sites of control: inadvertent stigma and exclusion in social marketing. Journal of Macromarketing 33(2):128-143.

Hastings G, Saren M. 2003. The critical contribution of social marketing: theory and application. Marketing Theory 3(3):305-322.

Hastings G, Stead M, Webb J. 2004. Fear appeals in social marketing: Strategic and ethical reasons for concern. Psychology and Marketing 21(11):961-986.

Hastings G, McDermott L. 2006. Putting social marketing into practice. British Medical Journal 332(7551):1210-1212.

Hill SC, Thomsen SR, Page RM, Parrott N. 2005. Alcohol advertisements in youth-oriented magazines: Persuasive themes and responsibility messages. American Journal of Health Education 36(5):258-265.

John P, Smith G, Stoker G. 2009. Nudge nudge, Think think: Two strategies for changing civic behaviour. Political Quarterly 80(3):361-370.

Kenyon AJ, Wood EH. 2011. Exploring government-led social marketing campaigns: Alcohol, think before you drink...Too much. International Journal of Management Cases 141-150.

Kettunen T, Poskiparta M, Liimatainen L. 2001. Empowering counselling--a case study: nurse-patient encounter in a hospital. Health Education Research 16(2):227-238.

Klatsky AL. 2004. Alcohol and cardiovascular health. Integrative and Comparative Biology 44(4):324-328.

Kotler P, Roberto N, Lee N. 2002. Social marketing: Improving the quality of life. Sage Publications.

Lang AR, Goeckner DJ, Adesso VJ, Marlatt GA. 1975. Effects of alcohol on aggression in male social drinkers. Journal of Abnormal Psychology, 84(5):508-518.

Lewis I, Watson B, Tay R. 2007. Examining the effectiveness of physical threats in road safety advertising: The role of the third-person effect, gender, and age. Transportation Research Part F: Traffic Psychology and Behaviour 10(1):48-60.

Marteau T. 2011. Judging nudging: can nudging improve population health?. British Medical Journal 342:263-265.

Neafsey EJ, Collins MA. 2011. Moderate alcohol consumption and cognitive risk. Neuropsychiatric Disease and Treatment 7:465-484.

Pang B, Kubacki K. 2015. The four Es of social marketing: ethicality, expensiveness, exaggeration and effectiveness. Journal of Social Marketing 5(1): 83-99.

Park CL. 2004. Positive and negative consequences of alcohol consumption in college students. Journal ofAddictive Behaviors 29(2):311-332.

Park CL, Grant C. 2005. Determinants of positive and negative consequences of alcohol consumption in college students: alcohol use, gender, and psychological characteristics. Journal of Addictive Behaviors 30(4):755-765.

Pettigrew S, Pescud M, Jarvis W, Dave W. 2013. Teens' blog accounts of the role of adults in youth alcohol consumption. Journal of Social Marketing 3(1):28-40.

Prasad, BD. 2008. Content analysis. A method in social science research. In: Lal Das DK, Bhaskaran, V (eds.) Research methods for Social Work, New Delhi:Rawat, pp.173193.

Rappaport J. 1981. In praise of paradox: A social policy of empowerment over prevention. American Journal of Community Psychology. 9(1):1-25.

Rehm J, Room R, Graham K, Monteiro M, Gmel , Sempos CT. 2003. The relationship of 
average volume of alcohol consumption and patterns of drinking to burden of disease: an overview. Addiction 98(9):1209-1228.

Rissel C. 1994. Empowerment: the holy grail of health promotion?. Health Promotion International 9(1):39-47.

Rundle-Thiele S, Ball K, Gillespie M. 2008. Raising the bar: from corporate social responsibility to corporate social performance. Journal of Consumer Marketing 25(4):245-253.

Sacco RL, Elkind M, Boden-Albala B, et al. 1999. The protective effect of moderate alcohol consumption on ischemic stroke. The Journal of the American Medical Association 281(1):53-60.

Sheehan M, Ridge D. 2001. You become really close ... You talk about the silly things you did, and we laugh: The role of binge drinking in female secondary students' lives. Substance Use and Misuse 36(3):347-372.

Steele CM, Josephs RA. 1990. Alcohol myopia. Its prized and dangerous effects. American Psychologist 45(8):921-933.

Siemieniako D, Kubacki K. 2011. Exploring college students’ perceptions of negative consequences of binge drinking through consumer collages. European Advances in Consumer Research 9:255-263.

Szmigin I, Griffin C, Mistral W, Bengry-Howell A, Weale L, Hackley C. 2008. Re-framing 'binge drinking' as calculated hedonism: empirical evidence from the UK. International Journal of Drug Policy 19(5):359-366.

Tay R. 2005. The effectiveness of enforcement and publicity campaigns on serious crashes involving young male drivers: Are drink driving and speeding similar?. Accident Analysis and Prevention 37(5):922-929.

Viljoen EN, Terblanche-Smit M, Terblanche NS. 2009. Good idea, bad idea: A study of young adults' opinions on anti-drunken driving campaigns. South African Journal for Communication 35(1):119-137.

Williams AF. 1966. Social drinking, anxiety and depression Journal of Personality and Social Psychology 3:689-693.

Wechsler H, Davenport A, Dowdall G, Moeykens B, Castillo S. 1994. Health and behavioral consequences of binge-drinking in college - a national survey of students at 140 campuses. The Journal of the American Medical Association, 272(21):1672-1677.

Wechsler H, Nelson TF. 2008. What we have learned from the Harvard School of Public Health College Alcohol Study: Focusing attention on college student alcohol consumption and the environmental conditions that promote it. Journal of Studies on Alcohol and Drugs 69(4):481.

World Health Organization. 2014. Global status report on alcohol and health 2014. http://www.who.int/substance_abuse/publications/global_alcohol_report/en/ [13/01/2015]

Wright L. 1999. Young people and alcohol: What 11-24 year-olds know, think and do: A literature review. Health Authority. London. UK.

Yanovitzky I, Stryker J. 2001. Mass media, social norms, and health promotion efforts: A longitudinal study of media effects on youth binge drinking. Communication Research 28(2):208-239. 
Table 1: Analytical framework

\begin{tabular}{|c|c|c|c|c|c|c|c|c|c|}
\hline \multicolumn{4}{|c|}{ Social marketing advertising approaches } & \multicolumn{3}{c|}{ Consequences of alcohol consumption } \\
\hline $\begin{array}{c}\text { Freedom } \\
\text { of choice }\end{array}$ & $\begin{array}{c}\text { Questions, } \\
\text { storytelling or } \\
\text { behavioural } \\
\text { language }\end{array}$ & $\begin{array}{c}\text { Efforts by people } \\
\text { to engage in } \\
\text { personal } \\
\text { development }\end{array}$ & $\begin{array}{c}\text { No } \\
\text { freedom } \\
\text { of choice }\end{array}$ & $\begin{array}{c}\text { Nudging and } \\
\text { conforming to } \\
\text { imposed } \\
\text { authoritarian } \\
\text { norms. }\end{array}$ & $\begin{array}{c}\text { Emotions: } \\
\text { Fear, shame } \\
\text { and guilt }\end{array}$ & $\begin{array}{c}\text { Mental } \\
\text { well-being }\end{array}$ & $\begin{array}{c}\text { Physical } \\
\text { Health }\end{array}$ & $\begin{array}{c}\text { Social } \\
\text { well-being }\end{array}$ & $\begin{array}{c}\text { Mental } \\
\text { health }\end{array}$ \\
$\begin{array}{c}\text { Physical } \\
\text { health }\end{array}$ & $\begin{array}{c}\text { Social } \\
\text { well-being }\end{array}$ \\
\hline
\end{tabular}

Table 2: The percentage of use of the main approaches and messages

\begin{tabular}{|c|c|c|c|c|}
\hline \multirow{2}{*}{ Total } & \multicolumn{2}{|c|}{ Approach } & \multicolumn{2}{c|}{$\begin{array}{c}\text { Consequences of alcohol } \\
\text { consumption }\end{array}$} \\
\cline { 2 - 5 } & Empowering & Patronizing & Positive & Negative \\
\hline Campaigns $(\mathrm{n}=14)$ & $50 \%(7)$ & $71 \%(10)$ & $36 \%(5)$ & $79 \%(11)$ \\
\hline Ads $(\mathrm{n}=29)$ & $55 \%(16)$ & $86 \%(25)$ & $41 \%(12)$ & $93 \%(27)$ \\
\hline
\end{tabular}

Table 3: The percentage of use of the subcategories

\begin{tabular}{|c|c|c|c|c|c|c|c|c|c|c|c|c|}
\hline \multirow[b]{3}{*}{ Total } & \multicolumn{6}{|c|}{ Approach } & \multicolumn{6}{|c|}{ Consequences of alcohol consumption } \\
\hline & \multicolumn{3}{|c|}{ Empowering } & \multicolumn{3}{|c|}{ Patronizing } & \multicolumn{3}{|c|}{ Positive } & \multicolumn{3}{|c|}{ Negative } \\
\hline & $\begin{array}{l}\text { Freedom of } \\
\text { choice }\end{array}$ & $\begin{array}{c}\text { Questions, } \\
\text { storytelling } \\
\text { or } \\
\text { behavioural } \\
\text { language }\end{array}$ & $\begin{array}{c}\text { Efforts by } \\
\text { people to } \\
\text { engage in } \\
\text { personal } \\
\text { developmen } \\
t\end{array}$ & $\begin{array}{c}\text { No freedom } \\
\text { of choice }\end{array}$ & $\begin{array}{c}\text { Nudging } \\
\text { and } \\
\text { conforming } \\
\text { to imposed } \\
\text { authoritari } \\
\text { an norms }\end{array}$ & $\begin{array}{c}\text { Fear, } \\
\text { shame and } \\
\text { guilt }\end{array}$ & $\begin{array}{l}\text { Mental } \\
\text { Health }\end{array}$ & $\begin{array}{c}\text { Physical } \\
\text { Health }\end{array}$ & $\begin{array}{c}\text { Social well- } \\
\text { being }\end{array}$ & $\begin{array}{l}\text { Mental } \\
\text { health }\end{array}$ & $\begin{array}{l}\text { Physical } \\
\text { health }\end{array}$ & $\begin{array}{c}\text { Social well- } \\
\text { being }\end{array}$ \\
\hline $\begin{array}{c}\begin{array}{c}\text { Campaigns } \\
(n=14)\end{array} \\
\end{array}$ & $28.57 \%(4)$ & $28.57 \%(4)$ & $35.7 \%(5)$ & $35.7 \%(5)$ & $28.57 \%(4)$ & 71.43\% (10) & $14.29 \%(2)$ & 0 & $21.43 \%(3)$ & $21.43 \%(3)$ & $78.57 \%(11)$ & $71.43 \%(10)$ \\
\hline Ads $(n=29)$ & $31.03 \%(9)$ & $37.93 \%(11)$ & $17.24 \%(5)$ & $20.69 \%(6)$ & $41.38 \%(12)$ & $72.41 \%(21)$ & $10.34 \%(3)$ & 0 & $31.03 \%(9)$ & $10.34 \%(3)$ & $75.86 \%(22)$ & $65.52 \%(19)$ \\
\hline
\end{tabular}

